\title{
RENTABILITAS DAN PENYERAPAN TENAGA KERJA AGROINDUSTRI SALE PISANG GULUNG \\ (Studi Kasus pada Perusahaan “UD Rizki Barokah" di Desa Sukahurip Kecamatan Pamarican Kabupaten Ciamis)
}

\author{
WIKA RESTIKA ${ }^{1 *}$, DINI ROCHDIANI ${ }^{2}$, BUDI SETIA ${ }^{1}$ \\ ${ }^{1}$ Fakultas Pertanian Universitas Galuh Ciamis \\ ${ }^{2}$ Fakultas Pertanian Universitas Padjajaran \\ *Email: wikarestika89@gmail.com
}

\begin{abstract}
ABSTRAK
Agroindustri sale pisang gulung di Desa Sukahurip sudah bejalan cukup lama yaitu 10 tahun dan memiliki produk dengan kualitas tinggi dan diharapkan dengan adanya industri pengolahan akan membuat hasil pertanian menjadi suatu produk yang mempunyai nilai tambah dan bernilai ekonomi yang tinggi, sehingga mampu meningkatkan keuntungan. Besarnya keuntungan yang diterima dapat digunakan sebagai tolok ukur dalam melihat perkembangan agroindustri Sale Pisang gulung tersebut dalam jangka panjang. Penelitian ini bertujuan untuk mengetahui 1) Biaya, penerimaan dan pendapatan, 2) Rentabilitas, 3) Penyerapan tenaga kerja agroindustri sale pisang gulung "UD Rizki Barokah" di Desa Sukahurip Kecamatan Pamarican Kabupaten Ciamis. Penelitian ini dilaksanakan pada bulan Februari 2020. Responden dalam penelitian ini adalah pemilik agroindustri "UD Rizki Barokah". Jenis penelitan yang digunakan dalam penelitian ini adalah penelitian kuantitatif dan metode penelitian yang digunakan berupa data primer dan data skunder. Teknik penarikan sampel yang digunakan yaitu purposive sampling. Hasil penelitian menunjukan dalam satu kali proses produksi menghasilkan sale pisang gulung sebanyak $112 \mathrm{~kg}$ dengan harga $\mathrm{Rp} 30.000,00$. Berdasarkan hasil perhitungan biaya total $\mathrm{Rp} 3.158 .845,87$, penerimaan $\mathrm{Rp} 3.360 .000,00$, pendapatan $\mathrm{Rp}$ $201.154,13$, Rentabilitas 0,06 \% dari total biaya yang dikeluarkan, Banyaknya tenaga kerja yang terserap dalam satu kali proses produksi agroindustri sale pisang gulung sebanyak 13 orang dengan penyerapan tenaga kerja $0,32 \%$.
\end{abstract}

Kata Kunci : Rentabilitas, tenaga kerja, agroindustri.

\section{ABSTRACT}

The sale of rolled banana agroindustry in Sukahurip Village has been around for a long time, namely 10 years and has high quality products and it is hoped that the processing industry will make agricultural products into products that have added value and high economic value, so as to increase profits. The amount of profit received can be used as a benchmark in seeing the development of the Banana Roll Sale agro-industry in the long term. This study aims to determine 1) Cost, revenue and income, 2) Profitability, 3) Absorption of labor in the agro-industrial sale of banana rolls "UD Rizki Barokah" in Sukahurip Village, Pamarican District, Ciamis Regency. This research was conducted in February 2020. Respondents in this study were owners of the agro-industry "UD Rizki Barokah". The type of research used in this research is quantitative research and the research methods used are primary data and secondary data. The sampling technique used was purposive sampling. The results showed in one production process resulted in $112 \mathrm{~kg}$ of sale banana rolls at a price of Rp. 30,000.00. Based on the calculation of the total cost of Rp. 3.158.845,87, revenue of Rp. 3,360,000.00, income of Rp. 210.154,13, Profitability 0,06\% of the total costs incurred, the amount of labor absorbed in one sale banana agro-industrial production process roll of as many as 13 people with a labor absorption of $0.32 \%$.

Keywords: Rentability, employment, agroindustry 


\section{PENDAHULUAN}

Agroindustri memiliki peranan strategis dalam upaya pemenuhan kebutuhan bahan pokok, perluasan kesempatan kerja, pemberdayaan produksi dalam negeri, dan pengembangan sektor perekonomian. Hal ini didukung dengan adanya keunggulan karakteristik yang dimiliki agroindustri, yaitu penggunaan bahan baku dari sumber daya alam yang tersedia di dalam negeri (Soekartawi, 2001).

Salah satu agroindustri skala kecil yang banyak berkembang di Desa Sukahurip Kecamatan Pamarican Kabupaten Ciamis adalah agroindustri Sale Pisang. Sale Pisang ini terbuat dari buah pisang yang sudah matang.Kandungan yang terdapat dalam buah pisang adalah potassium atau kalium, serat dan zat besi.

UD Rizki Barokah adalah perusahaan sale pisang gulung yang memiliki produk dengan kualitas tinggi dan diharapkan dengan adanya industri pengolahan akan membuat hasil pertanian menjadi suatu produk yang mempunyai nilai tambah dan bernilai ekonomi yang tinggi, sehingga mampu meningkatkan keuntungan. Besarnya keuntungan yang diterima dapat digunakan sebagai tolok ukur dalam melihat perkembangan agroindustri Sale Pisang gulung dalam jangka panjang. Diharapkan dengan adanya agroindustri ini dapat mengurangi pengangguran dan memperluas lapangan kerja. Selain itu, dapat memberikan dampak secara langsung maupun secara tidak langsung terhadap perekonomian nasional.

Tujuan dari penelitian ini adalah untuk mengetahui :

1) Biaya, penerimaan, dan pendapatan pada agroindustri Sale Pisang Gulung "UD Rizki Barokah” di Desa Sukahurip Kecamatan Pamarican Kabupaten Ciamis.

2) Rentabilitas pada agroindustri Sale Pisang Gulung “UD Rizki Barokah” di Desa Sukahurip Kecamatan Pamarican Kabupaten Ciamis.

3) Penyerapan tenaga kerja pada agroindustri Sale Pisang Gulung "UD Rizki Barokah" di Desa Sukahurip Kecamatan Pamarican Kabupaten Ciamis.

\section{METODE PENELITIAN}

Metode penelitian yang digunakan adalah metode studi kasus pada agroindustri Sale Pisang Gulung "UD Rizki Barokah" di Desa Sukahurip Kecamatan Pamarican Kabupaten Ciamis. Menurut Sukandar Rumidi (2006), metode studi kasus merupakan penelitian yang mendalam (intens) mengenai studi kasus tersebut dan 
tidak bisa digeneralisasikan pada yang luar kasus tersebut.

Data yang digunakan dalam penelitian ini berupa data primer dan data sekunder. Data Primer ialah data yang diperoleh melalui wawancara langsung ke pengusaha sale pisang gulung "UD Rizki Barokah" dengan menggunakan daftar pertanyaan, sedangkan data sekunder adalah data yang diperoleh dari instansi atau dinas terkait yang ada hubungannya dengan penelitian.

Teknik penarikan sampel yang dilakukan pada penelitian adalah metode purposive sampling yaitu teknik untuk menentukan sampel penelitian dengan beberapa pertimbangan tertentu yang bertujuan agar data yang diperoleh nantinya bisa lebih representatif (Sugiyono,2010).

Yang menarik dari tempat penelitian di "UD Rizki Barokah" adalah cara pembuatan nya berbeda dengan yang lain yaitu dengan menggunakan bahan baku babanggi pisang dengan cara di gulung dan pemasaran nya sudah ke berbagai sentra oleh-oleh di Indonesia seperti Kalimantan dan Yogyakarta.

Besarnya biaya, penerimaan dan pendapatan yang diterima dari agroindustri sale pisang gulung dapat diketahui dengan menggunakan rumus dari sebagai berikut :
Besarnya biaya total (Total Cost) dihitung dengan menggunakan rumus sebagai berikut (Suratiyah, 2015) :

$$
\text { TC }=\text { TFC }+ \text { TVC }
$$

Dimana :

TC =Total Cost (Biaya Total)

TFC $=$ Total Fixed Cost $($ Biaya Tetap Total)

TVC $=$ Total Variable Cost (Biaya Variabel Total)

Besarnya penerimaan diketahui dengan menggunakan rumus sebagai berikut (Suratiyah, 2015) :

$$
\mathbf{T R}=\mathbf{Y} \times \mathbf{P y}
$$

Dimana :

$\mathrm{TR}=$ Total Revenue (Penerimaan Total)

$\mathrm{Y}=$ Jumlah Produksi

Py $=$ Harga

Besarnya pendapatan dihitung dengan menggunakan rumus sebagai berikut (Suratiyah, 2015) :

$$
\text { Pd }=\text { TR }- \text { TC }
$$

Dimana

$\mathrm{Pd}=$ Pendapatan

$\mathrm{TR}=$ Total Revenue $($ Penerimaan Total $)$

$\mathrm{TC}=$ Total Cost (Biaya Total)

Besarnya nilai rentabilitas dihitung dengan menggunakan rumus sebagai berikut (Riyanto, 2010) :

$$
\mathrm{R}=\frac{\mathrm{L}}{\mathrm{M}} \times 100 \%
$$

Dimana :

$\begin{aligned} \mathrm{R}= & \begin{array}{l}\text { Rentabilitas suatu perusahaan yang } \\ \text { menunjukkan perbandingan antara }\end{array}\end{aligned}$ 
laba dengan modal yang digunakan untuk menghasilkan laba (\%).

$\mathrm{L}=$ Jumlah laba yang diperoleh pada periode tertentu $(\mathrm{Rp})$.

$\mathrm{M}=$ Modal dari seluruh biaya yang digunakan untuk menghasilkan laba (Rp).

Dihitung dengan menggunakan rumus menurut (Suratiyah, 2015), yaitu :

Penyerapan Tenaga Kerja

$$
\mathrm{TK}=\frac{\text { Jumlah Tenaga Kerja yang Diserap dalam Industri }}{\text { Jumlah Angkatan Kerja Desa }} \times 100 \%
$$

\section{PEMBAHASAN}

Analisis usaha agroindustri sale pisang gulung terdiri dari analisis biaya, penerimaan, pendapatan, $\mathrm{R} / \mathrm{C}$, rentabilitas dan penyerapan tenaga kerja yang dihitung selama satu kali proses produksi.

Tabel 7. Rincian Biaya Tetap dan Biaya Variabel Agroindustri Sale Pisang Gulung UD Rizki Brokah dalam Satu Kali Proses Produksi

\begin{tabular}{clrr}
\hline No. & Biaya & Jumlah (Rp) \\
\hline 1. & Biaya Tetap & \\
& - & PBB & 17,36 \\
& - & Penyusutan Alat & $43.637,54$ \\
& - & PIRT & 868,05 \\
& - & NPWP & 347,22 \\
& - & Bunga Modal Tetap & 448,70 \\
& & Jumlah & $\mathbf{4 5 . 3 1 8 , 8 7}$ \\
\hline 2. & Biaya Variabel & \\
- & Babanggi pisang & 1.350 .000 \\
- & Margarin & 60.000 \\
- & Tepung perigu & 120.000 \\
- & Tepung beras & 240.000 \\
- & Gula pasir & 70.000 \\
- & Kayu Bakar & 70.000 \\
- & Minyak Goreng & 375.000 \\
- & Kemasan 4 kg & 87.500 \\
- & Garam & 2.000 \\
- & Listrik & 1.000 \\
- & Label & 4.200 \\
- & Komunikasi & 13.000 \\
- & Transportasi & 120.000 \\
- & Tenaga Kerja & 570.000 \\
- & Bunga modal variabel & 30.827 \\
& Jumlah & $\mathbf{3 . 1 1 3 . 5 2 7}$ \\
\hline
\end{tabular}

Berdasarkan tablel 7 Biaya penyusutan alat tergantung dari harga beli alat-alat produksi serta berapa lama alat dan bangunan tersebut dapat dipergunakan. Besarnya biaya tetap dalam satu kali proses produksi yaitu Rp. $45.318,87$ per satu kali proses produksi.

Biaya variabel adalah biaya yang besar kecil nya dipengaruhi pada setiap satu kali proses produksi, yang dikeluarkan perajin dalam agroindustri sale pisang gulung meliputi sarana produksi/bahan baku, upah tenaga kerja dan bunga modal variable. Besarnya biaya variable yang dikeluarkan perajin yaitu Rp. 3.113.527 per satu kali proses produksi. 
Tabel 8. Hasil produksi, Penerimaan , Pendapatan, dan R/C pada agroindustri Sale Pisang Gulung "UD Rizki Barokah" .

\begin{tabular}{clr}
\hline No. & \multicolumn{1}{c}{ Uraian } & Jumlah \\
\hline 1. & Volume Produksi (Kg) & 112,00 \\
2. & Harga Produk (Rp) & $30.000,00$ \\
3. & Penerimaan (Volume x Harga) (Rp) & $3.360 .000,00$ \\
4. & Biaya Total & $3.158 .845,87$ \\
5. & Pendapatan & $201.154,13$ \\
6. & R/C & 1,06 \\
\hline
\end{tabular}

Tabel 8 menunjukan bahwa besarnya penerimaan pengrajin dalam satu kali proses produksi Rp. 3.360.000,00. Sedangkan biaya Total Rp. 3.158.845,87, sehingga pendapatan yang diterima Rp. 201.154,13 per satu kali proses produksi, dengan nilai R/C 1,06 sehingga usaha yanh dilakukan layak atau menguntungkan. Artinya setiap harga yang dikeluarkan Rp. 1 memperoleh penerimaan Rp. 1,06 dan pendapatan Rp. 0,06.

\section{Rentabilitas Agroindustri Sale Pisang Gulung}

Rentabilitas digunakan untuk melihat kemampuan agroindustri sale pisang gulung dalam menghasilkan laba dari modal pada periode tertentu, dalam penelitian ini, dihitung dalam satu kali proses produksi. Besarnya rentabilitas sale pisang gulung yang diperoleh 0,06 persen dari total biaya yang dikeluarkan. Hal ini menunjukan bahwa agroindustri sale pisang gulung di Desa Sukahurip mampu menghasilkan laba pada setiap proses produksinya.
Penyerapan Tenaga Kerja Aroindustri Sale Pisang Gulung

Tenaga kerja yang terlibat dalam agroindustri sale pisang gulung berjumlah 13 orang dan produksi menghabiskan waktu satu hari. Tenaga kerja yang terlibat bila di bandingkan dengan jumlah penduduk di desa Sukahurip pada usia kerja dapat diketahui tingkat penyerapan tenaga kerja nya yaitu 0,32 persen. Angka tersebut diperoleh dari tenaga yang diserap berjumlah 13 orang di bagi dengan jumlah angkatan kerja dan di kali 100\%. Walaupun persentase nya kecil namun agroindustri tersebut mampu memberikan kontribusi terhadap penyerapan tenaga kerja di Desa Sukahurip Kecamatan Pamarican Kabupaten Ciamis.

\section{KESIMPULAN DAN SARAN}

\section{Kesimpulan}

Berdasarkan hasil dan pembahasan, maka kesimpulan dari penelitian ini sebagai berikut :

1) Biaya yang dikeluarkan agroindustri sale pisang gulung "UD Rizki Barokah" di Desa Sukahurip Kecamatan PamaricanKabupaten 
Ciamis per satu kali proses produksi yaitu Rp. 3.158.845,87, penerimaan Rp. 3.360.000,00 dan pendapatan Rp. 201.154,13, dan nilai R/C yang diperoleh yaitu 1,06 .

2) Nilai rentabilitas yang diperoleh agroindustri sale pisanggulung "UD Rizki Barokah" di Desa Sukahurip Kecamatan Pamarican Kabupaten Ciamis per satu kali proes produksi yaitu 0,06 persen dari modal yang dikeluarkan.

3) Penyerapan tenaga kerja yang di serap oleh agroindustri sale pisanggulung “UD Rizki Barokah” di Desa Sukahurip Kecamatan Pamarican Kabupaten Ciamis yaitu 0,32 persen dari tolal angkatan kerja.

\section{Saran}

Berdasarkan kesimpulan tersebut maka disarankan sebagai berikut, melihat pendapatan yang diperoleh dan rentabilitas pada agroindustri sale pisang gulung "UD Rizki Barokah" yang cukup besar, maka usaha tersebut perlu dikembangkan dalam bentuk industri dengan cara meningkatkan produksi dan skala usaha sale pisang gulung dengan peningkatan skala usaha, diharapkan dapat menyerap tenaga kerja lebih banyak lagi dengan tujuan mengurangi pengangguran di Desa Sukahurip Kecamatan Pamarican Kabupaten Ciamis. .

\section{DAFTAR PUSTAKA}

Soekartawi, 2001. Pengantar Agroindustri. Edisi 1. Jakarta : Cetakan 2. PT Raja Grafindo Persada. Hal 152.

Sugiyono. 2010. MetodePenelitian Pendidikan Pendekatan Kuantitatif, Kualitatif,dan R\&D. Bandung : Alfabeta

Suprapto. 2008. Karakteristik Penerapan dan Pengembangan Agroindustri Hasil Pertanian di Indonesia. Universitas Mercu Buana. Jakarta.

Suratiyah, Ken. 2009. Ilmu Usahatani. Jakarta : Penebar Swadaya.

Wibisono. Handoyo, 1993, Manajemen Modal Kerja, Yogyakarta, Penerbit Universitas Atmajaya, Yogyakarta.

Saragih, B. 2010. Paradigma Baru Pembangunan Ekonomi Berbasis Pertanian. IPB Press. Bogor. 